\title{
Development and Validation of an Instrument Measuring Cyberbullying Among Malaysian Youths
}

\author{
Akmar Hayati Ahmad Ghazali ${ }^{1,2 *}$, Asnarulkhadi Abu Samah ${ }^{1,3}$, Siti Zobidah Omar ${ }^{1,2}$, Haslinda \\ Abdullah $^{1,3}$, Aminah Ahmad ${ }^{1}$, Hayrol Azril Mohamed Shaffril ${ }^{1}$ \\ ${ }^{1}$ Institute for Social Science Studies, Universiti Putra Malaysia \\ ${ }^{2}$ Faculty of Modern Language and Communication, Universiti Putra Malaysia \\ ${ }^{3}$ Faculty of Human Ecology, Universiti Putra Malaysia
}

\begin{abstract}
This study sought to develop and validate an instrument measuring cyberbullying among Malaysian youths. Exploratory factor analysis (EFA) was employed to determine the best sub-factors and items for the instrument, while confirmatory factor analysis (CFA) was performed to test and validate the measurement model. Results from EFA on 38 items showed that the items were pooled into four sub-factors. Meanwhile, results from CFA indicated that eight items had to be discarded in order to confirm that the model was fit. Overall, the final version of the instrument consisted of four cyberbullying sub-factors, namely, impersonation (13 items), cyberstalking and harassment (nine items), flaming (four items), and elimination (four items).
\end{abstract}

Keywords: Instrument development; Youths; Cyberbullying; Youth development

Copyright: This is an open access article distributed under the terms of the Creative Commons Attribution-NonCommercialShareAlike 4.0 International (CC BY-NC-SA 4.0) license which permits unrestricted use, distribution, and reproduction in any medium, for non-commercial purposes, provided the original work is properly cited

\section{INTRODUCTION}

Cyberbullying can be understood as intentional and repetitive harmful behaviour through the use of information and communication technology (Smith et al., 2008). Compared to traditional bullying, cyberbul-

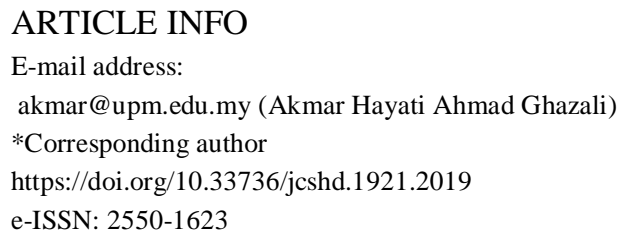

Manuscript received: 28 May 2019; Accepted: 8 August 2019; Date of publication: 30 September 2019. lying has a higher tendency to be committed by youths as the virtual world offers them advantages such as an extra degree of protection and an anonymous identity (Balakrishnan, 2015). As a result, those who do not dare to commit traditional bullying might arguably turn to cyberbullying (Mohamad Salleh \& Zainal, 2014). In Malaysia, cyberbullying is a matter of utmost concern. A recent cyber-safety campaign found that $83 \%$ of young people in Malaysia were vulnerable to online risks due to minimal protective actions, while $70 \%$ identified themselves as being subjects to various forms of online harassment (Digi, 2015). In another 
study by Balakrishnan (2015), it was identified that $40 \%$ of young people in Malaysia had committed cyberbullying.

From a psychological perspective, cyberbullying needs to be prevented as it is a social issue that significantly affects young people in Malaysia. Studies across the globe have discussed the various impacts of cyberbullying on young people. For example, studies conducted by Aricak and Ozbay (2016) and Vranjes et al. (2017) have noted that cyberbullying is associated with feelings of anger, frustration, and sadness. Some other researchers have confirmed that cyberbullying victims experience isolation, loneliness, anxiety, depression, and lower self-esteem (Kokkinos et al., 2014; Landoll et al., 2015). Besides, Landoll et al. (2015) have also confirmed that cyber-victims would be more likely to engage in antisocial behaviours such as absenteeism.

Meanwhile, Bauman et al. (2013) and Hinduja and Patchin (2010) have examined the impact of cyberbullying on delinquency, self-harm, and suicidal tendencies. Furthermore, Hinduja and Patchin (2008) and Schenk et al. (2013) have found connections between cyber-victims and school problems and substance use. In short, all of these stud- ies have concluded that cyberbullying results in a considerable number of negative impacts on its victims. Thus, something needs to be done in order to understand better the issue of cyberbullying so that it can be tackled.

In order to fully understand the issue of cyberbullying, a tool would have to be developed to measure current cyberbullying activities. Moreover, such a tool would have to be empirically-validated before cyberbullying can be studied. In Malaysia, local studies on cyberbullying have also been conducted, for instance, studies by Balakrishnan $(2017,2015)$ and Mohamad Salleh and Zainal (2014). Nonetheless, not many of these local studies have attempted to develop an empirically-validated instrument measuring cyberbullying, especially within the context of youths in Malaysia. Furthermore, the definition of youths in Malaysia refers to young people between 15 and 40 years old. This age group does not fit into the age group categories studied using previously developed instruments, as reported in the literature (see Table 1). Hence, the main aim of the present study was to develop and validate an instrument measuring cyberbullying among Malaysian youths as a response to the lack of available studies and

Table 1: Instruments measuring cyberbullying as reviewed in the literature

\begin{tabular}{llc}
\hline Researcher & Country & Respondents' age group \\
\hline Udris (2014) & Japan & $15-19$ years old \\
Del Rey et al. (2015) & Spain, Germany, Italy, Poland, United & $11-23$ years old \\
& Kingdom, and Greece & \\
Antoniodou et al. (2016) & Greece & $12-17$ years old \\
Shapka and Maghsoudi (2017) & British Columbia & $11-13$ years old \\
Alvarez-Garcia et al. (2016) & Spain & $12-18$ years old \\
Lam and Li (2013) & China & $11-16$ years old \\
Calvete et al. (2010) & Spain & $12-17$ years old \\
Topcu and Erdur-Baker (2010) & Turkey & $13-21$ years old \\
Stewart et al. (2014) & USA & $11-18$ years old \\
Garaigordobil (2015) & Spain & $12-18$ years old \\
Cetin et al. (2011) & Turkey & $14-19$ years old \\
Lee et al. (2015) & USA & $18-25$ years old \\
Coelho et al. (2016) & Portugal & $11-14$ years old \\
\hline
\end{tabular}


suitable instruments adequately measuring cyberbullying within the Malaysian context.

\section{BACKGROUND OF STUDY}

Several instruments measuring cyberbullying which had been developed in the past several years are reviewed to provide contextual background to the study. Udris (2014) developed an online disinhibition scale for Japanese high school students. Their study involved a total of 887 high school students aged between 15 and 19 years old. Based on exploratory factor analysis (EFA), two factors were identified, namely, benign disinhibition and toxic disinhibition. Benign disinhibition referred to the promotion of openness, kindness, and generosity, while toxic disinhibition denoted rude language, hatred, and threats. The final version of the instrument consisted of 11 items that we can measure online disinhibition.

Antoniodou et al. (2016) developed the Cyber-Bullying and Victimization Experiences Questionnaire-Greek (CBVEQ-G). Their study involved a total of 1,097 Greek adolescents aged between 12 and 17 years old. The CBVEQ-G intended to measure cyberbullying (CB) and cyber-victimisation (CM) behaviours, which were then further categorised into direct and indirect behaviours. Although all the behaviours, namely, the two-factor ( $\mathrm{CB}$ and $\mathrm{CM}$ ) and four-factor (direct $\mathrm{CB}$, indirect $\mathrm{CB}$, direct $\mathrm{CM}$, and indirect $\mathrm{CM}$ ) models were tested via confirmatory factor analysis (CFA), the results generally supported the two-factor model of $\mathrm{CB}$ and $\mathrm{CM}$ across gender and grade-level groups. The CFA confirmed that CBVEQ-G demonstrated good internal consistency and convergent validity, thus confirming that
CBVEQ-G was a valid and reliable selfreport measure of $\mathrm{CB}$ and $\mathrm{CM}$.

More recently, Shapka and Maghsoudi (2017) attempted to develop and validate an instrument measuring cyber-aggression and cyber-victimisation. Their study was conducted among 609 students aged between 11 and 13 years old at the Lower Mainland of British Columbia. A CFA concluded the construct validity, with strong support for a two-factor model, cyber-aggression perpetration (CAV-P) and cyber-victimisation $(\mathrm{CAV}-\mathrm{V})$. Structural invariance was confirmed for both boys and girls and students of Asian descent. The correlation between the two subscales met the requirement of concurrent validity. Finally, partial correlations with other social-emotional outcomes such as depression, anxiety, rumination, aggression, and school connectedness confirmed the instrument's convergent validity. The final version of the instrument consisted of 24 items.

Meanwhile, Lam and Li (2013) produced a scale to measure e-victimization (EVS) and e-bullying (EBS) for adolescents in China. Their study was conducted on 484 adolescents aged between 11 and 16 years old. Based on the EFA, a single factor model for EVS (i.e., five items with each factor loading that ranged from 0.64 to 0.85 ) and a two-factor model for EBS were identified (i.e., three items with each factor loading that ranged from 0.31 to 0.99). The Cronbach's alpha values confirmed evidence for good internal reliability with values ranging between 0.55 and 0.96. Further analysis of the correlations between the EVS and depression as well as the anxiety scales demonstrated positive and significant 
relationships; nevertheless, EBS was only correlated to depression.

Before Lam and Li's study (2013), Cetin et al. (2011) had developed a scale to measure cyberbullying and cyber-victimisation. Their study had been conducted among 404 students aged between 14 and 19 years old in Sakarya, Turkey. Five specialists had examined the content and face validity of the 45 items included in the scale leaving only 22 items remaining. EFA had resulted in three subfactors, namely cyber, verbal bullying, hidden identity, and cyber forgery accounting for $49.18 \%$ of the total variance. The same analysis had resulted in threefactor loadings for cyber-victimisation, accounting for $46.38 \%$ of the total variance.

Further calculation via CFA using the criterion-related validity concluded the correlation between the cyber-victimisation and cyberbullying, and the aggression scale was .27 and .36 , respectively. The internal consistency coefficients for cyber-victimisation and cyberbullying scales was .89 , and the split-half coefficients were .79. The testretest reliability confirmed a figure of .85 for cyber-victimisation and .90 for cyberbullying.

Furthermore, Alvarez-Garcia et al. (2016) developed a self-report scale to measure cyber-aggression in adolescents (CYBA) using a multifactorial model. Their study involved a total of 3,148 youths aged between 12 and 18 years old, from 19 schools in Asturias, Spain. With regards to factorial validity, the model fitted when it was represented by the structure of the CYBA which consisted of three factors (i.e., impersonation, visual-sexual cyber-aggression, and verbal cyber-aggression and exclusion) and four additional indicators that included vis- ual cyber-aggression-teasing/happy slapping. With regards to criterion validity, it was found that there was a positive relationship between CYBA and impulsivity and aggression at school and a negative relationship between CYBA and empathy. The reliability analysis, which was carried out concluded that each item and factor of the CYBA had exceeded the minimum reliability requirement. The final version of the questionnaire consisted of 15 items.

\section{The Present Study}

The current study is unique as it aimed to develop a reliable and empirically-validated instrument measuring cyberbullying among Malaysian youths. A review of existing literature identified that most of the literature in this area was conducted from a Western perspective; thus, an instrument measuring cyberbullying from a nonWestern perspective would be necessary. Furthermore, the existing literature has offered reliable and validated scales or instruments measuring a younger age group as most of the adolescents aged between 11 and 25 years old. Conversely, the current study sought to produce an instrument measuring an older age group, namely, youths aged between 18 and 40 years old. The study relied on two methods of analysis - the EFA and the CFA, to test the measurement model. The EFA is commonly used to uncover an underlying structure of a relatively large set of variables while the CFA is typically used to test model fit and validate the measurement model.

\section{METHODS}

\section{Participants and Sampling Procedures}


The mean for respondents' age was 21.2; most of them fell within the 20-22-year-old age group. A total of $66.9 \%$ of the respondents were either educated until tertiary level or still studying at the tertiary level of education while only $29.3 \%$ of them were working. A majority of the respondents were single (91.8\%) and the mean for their household income was RM 3,491.2, while a quarter of them earned between RM 1,001 and RM 2,000 a month. The respondents were considered to be experienced internet users, as most of them (54.8\%) had 6 or more years of experience using the Internet. A total of $25.0 \%$ of the respondents spent between 4 and 7 hours a day on the Internet, while $52.5 \%$ of them chose their home as the central place to use the Internet. A total of $27.8 \%$ of the respondents mainly used the Internet at night.

This study involved a total of 400 youths aged between 15 and 40 years old. Multistage cluster sampling was performed to select the respondents. During the first stage, all of the states in Malaysia were listed, and then a state was randomly selected (i.e., Selangor). During the second stage of sampling, all of the districts in Selangor were listed, and then a total of four districts were randomly selected (i.e., Petaling, Klang, Sabak Bernam, and Hulu Langat). Finally, during the third stage of sampling, a total of 100 youths were selected as respondents from each selected district, making the total number of respondents selected for the study to be 400 (i.e., $100 \times 4$ selected districts $=400$ ).

Before data collection, the research team members briefed the enumerators on the questionnaire and the areas of data collection. The enumerators were allowed to ask any questions to avoid any confusion during the actual data collection. The data collection was conducted for three months from January until March 2017. A survey was used as a data collection technique. The survey was conducted at places of interests for youths such as cyber cafés, telecentres, futsal courts, and public halls. The survey session was entirely conducted in Malay, and the respondents were allowed to ask any related questions to the enumerators. The research team members monitored the data collection process.

\section{Measures}

The items were developed following a combination of instruments developed by Lam and Li (2013), Cetin et al. (2011), and Calvete et al. (2010). All the items included in the instrument were designed to assess cyberbullying behaviours among youths accurately. At the first stage, all of the potential items identified by the researchers were pooled together to form a first item bank. The researchers then screened the items to ensure that all items would reflect the situation in Malaysia through a series of instrument development meetings. This process resulted in a total of 41 items being included in the instrument. Since it was a self-reported instrument, the respondents were asked to indicate the frequency of them performing individual cyberbullying acts in the past two weeks. The respondents were given a 5-point Likert scale which ranged between $0=$ Never and $4=$ Always for each of the items asked. Two experts performed the face validity on the instrument in cyberbullying. The experts advised the researchers to exclude three items which they thought were not related to cyberbullying in Malaysia. Further details on the pro- 
cess of the instrument development are expanded on the results section.

\section{Analysis}

The EFA was first performed in the instrument development process. It was conducted to uncover the underlying factors of a relatively large set of variables. In order to fulfil the minimum requirement for factor analysis, the value of Bartlett's test of sphericity must be less than .05 , and the Kaiser-
Meyer-Olkin (KMO) measure of sample adequacy value must at least exceed .600 (Mooi et al., 2018). After the factors were identified, the CFA was performed. A CFA is typically required to test the goodness-offit of a model, and its convergent validity and construct reliability. The model fit test resulted in the identification of fit indices and access to individual factor loading.

Table 2: Exploratory Factor Analysis results

\begin{tabular}{|c|c|c|c|c|}
\hline Item & Factor 1 & Factor 2 & Factor 3 & Factor 4 \\
\hline \multicolumn{5}{|l|}{ Impersonation } \\
\hline B20 & .758 & & & \\
\hline B23 & .717 & & & \\
\hline B19 & .693 & & & \\
\hline B18 & .677 & & & \\
\hline B16 & .653 & & & \\
\hline B17 & .643 & & & \\
\hline B21 & .634 & & & \\
\hline B11 & .602 & & & \\
\hline B24 & .592 & & & \\
\hline B10 & .575 & & & \\
\hline B22 & .573 & & & \\
\hline B14 & .564 & & & \\
\hline B 15 & .545 & & & \\
\hline \multicolumn{5}{|c|}{ Cyberstalking and harassment } \\
\hline B36 & & .761 & & \\
\hline B37 & & .723 & & \\
\hline B35 & & .722 & & \\
\hline B38 & & .714 & & \\
\hline B32 & & .701 & & \\
\hline B34 & & .656 & & \\
\hline B33 & & .654 & & \\
\hline B31 & & .638 & & \\
\hline \multicolumn{5}{|l|}{ Flaming } \\
\hline B5 & & & .659 & \\
\hline B6 & & & .645 & \\
\hline B1 & & & .642 & \\
\hline B4 & & & .631 & \\
\hline B3 & & & .573 & \\
\hline B7 & & & .563 & \\
\hline B2 & & & .552 & \\
\hline B8 & & & .523 & \\
\hline B12 & & & .521 & \\
\hline \multicolumn{5}{|l|}{ Elimination } \\
\hline B28 & & & & .741 \\
\hline B29 & & & & .733 \\
\hline B25 & & & & .721 \\
\hline B26 & & & & .714 \\
\hline B27 & & & & .686 \\
\hline No. of item & 13 & 8 & 9 & 5 \\
\hline Eigenvalue & 19.52 & 2.14 & 1.51 & 1.26 \\
\hline$\%$ of Variance & 20.71 & 16.51 & 15.44 & 11.65 \\
\hline
\end{tabular}




\section{RESULTS}

\section{Exploratory Factor Analysis}

The first step of the EFA was to examine the KMO measure of sampling adequacy and Bartlett's test of sphericity. The resultant value of the KMO test measure of sampling adequacy was .966 , which exceeded the recommended value of .600 (a value of $>0.9$ is considered a Marvellous) (Mooi et al., 2018). Meanwhile, Bartlett's test of sphericity resulted in a chi-square $=$
$12420.162, p<.000$, which meant the correlation matrix was not an identity matrix and was fit for factor analysis. Thus, EFA was then conducted and resulted in a four-factor solution; namely, impersonation, cyberstalking and harassment, flaming, and elimination. The EFA explained that $64.31 \%$ of the variance within the model while a total of three items, namely B9, B13, and B30, were excluded as their absolute values did not exceed .500 .

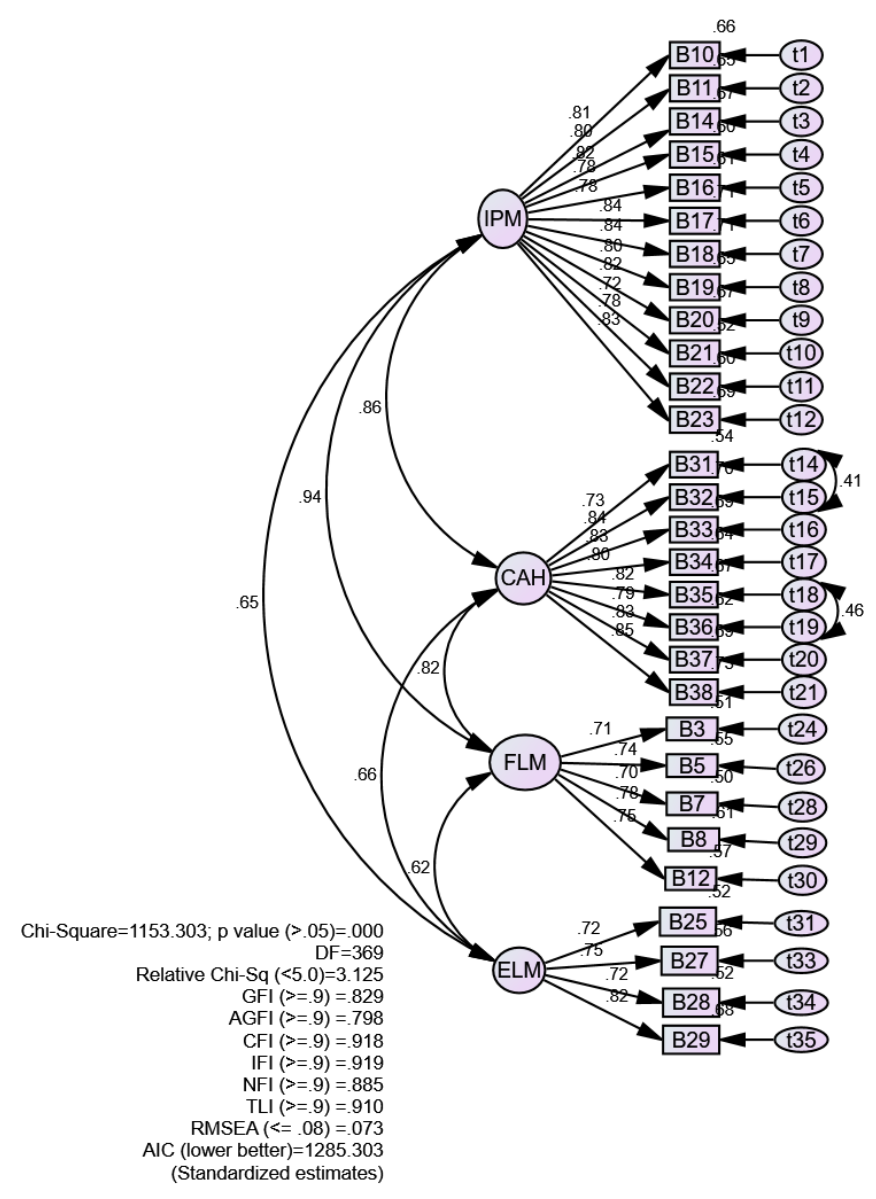

Figure 1: The measurement model for the present study

IPM = Impersonation;

$\mathrm{CAH}=$ Cyberstalking and harassment;

FLM = Flaming;

ELM = Elimination 
Akmar Hayati Ahmad Ghazali et al.

Table 3: Reliability analysis

\begin{tabular}{lcc}
\hline \multicolumn{1}{c}{ Sub-factor } & Internal Consistency & Split-half \\
\hline Impersonation & .954 & .930 \\
Cyberstalking and Harassing & .941 & .891 \\
Flaming & .841 & .806 \\
Elimination & .839 & .856 \\
\hline
\end{tabular}

The first factor (impersonation) consisted of 13 variables. The eigenvalue for this factor was 19.52 , and it explained $20.71 \%$ of the variance. The second factor (cyberstalking and harassment) consisted of eight items. The eigenvalue for this factor was 2.14, and it explained $16.51 \%$ of the variance. The third factor (flaming) consisted of nine items. The eigenvalue for this factor was 1.51 , and it explained $15.44 \%$ of the variance. Finally, the fourth factor (elimination) consisted of five items. The eigenvalue for the fourth factor was 1.26 , and it explained that $11.65 \%$ of the variance (see Table 2).

3.2 Confirmatory Factor Analysis

CFA was performed to test the model fit, as well as to test discriminant validity and assumptions. Seven items, namely, B24 (impersonation), B1, B2, B4, B6, B12 (flaming), and B26 (elimination) were excluded from the model as their factor loadings did not exceed the recommended minimum value of .70 . The final model resulted in $\chi^{2}(29)=1153.303 ; \chi^{2} / d f=3.125$; GFI $=$ $.829 ; \mathrm{AGFI}=.798 ; \mathrm{CFI}=.918 ; \mathrm{NFI}=.885$; $\mathrm{IFI}=.919 ; \mathrm{TLI}=.910 ;$ RMSEA $=.073$. Some of the resultant values were less than .900 as suggested by Chau (1997), Segars and Grovers (1993), Bentler (1990), Hatcher (1994), and Bentler and Bonett (1980); nevertheless, Hair et al. (2010) have explained that if three to four indices in a model pass the minimum requirement, the model can be considered as fit.
The factor loadings for the four sub-factors are illustrated in Figure 1. The factor impersonation consisted of 12 items with factor loadings ranging between .72 and .89 . The sub-factor cyberstalking and harassment consisted of eight items with factor loadings ranging between .73 and .85 . Another subfactor, flaming, consisted of five items which had a resultant factor loading ranging between .71 and .78. Finally, the last subfactor, elimination, consisted of four items with a factor loading ranging between .72 and .82 .

The study relied on two reliability methods to examine the reliability of the instrument. The first was the internal consistency method, while the second one was the split-half method. For the internal consistency method, all of the sub-factors (Impersonation: .956, Cyberstalking and Harassing: .945, Flaming: .823, Elimination: .839) passed the threshold value of .700 recommended by Nunnally (1978). The split-half reliability analysis also confirmed the reliability of the instrument as all of the sub-factors (Impersonation: .936, Cyberstalking and Harassing: .893, Flaming: .782, Elimination: .857) recorded values that exceeded .700 (see Table 3).

Table 4 displays the mean score for each of the items included in the variables. The highest mean score recorded for the subfactors was elimination $(M=.51)$, and the item that recorded the highest mean score under this variable was B28 (acting like 
another person did not exist, $M=.96)$. It was followed by the sub-factor flaming ( $M$ $=.50$ ), and the item that recorded the highest mean score under this variable was B7 (inviting others to social applications which included gossiping or inappropriate chats, $M=.64)$. The third highest mean score recorded for the sub-factors was impersonation as the item $\mathrm{B} 21$ (pretending to be someone else in the online world) recorded the highest mean score under this variable $(M=.55)$. The lowest mean score recorded for the subfactors were cyberstalking, and harassment $(M=.36)$ and the item that emerged with the highest mean score $(M=.47)$ under this variable was B31 (making anonymous calls to scare or frighten others).

\section{DISCUSSION}

The study succeeded in developing an instrument measuring cyberbullying activities among Malaysian youths. Interestingly, in contrast to other previous studies, the instrument was intended to measure cyberbullying among an older age group (15 to 40 years old). The EFA resulted in a four-factor solution; namely, flaming, cyberstalking and harassment, elimination, and impersonation. The factors explained $64.31 \%$ of the variance within the model while the measurement model resulted in $\chi^{2}(29)=1153.303$; $\chi^{2} / d f=3.125 ; \mathrm{GFI}=.829 ; \mathrm{AGFI}=.798 ; \mathrm{CFI}$ $=.918 ; \mathrm{NFI}=.885 ; \mathrm{IFI}=.919 ; \mathrm{TLI}=.910 ;$ RMSEA $=.073$ which exceeded the mini-

Table 4: Means for the sub-factors and cyberbullying items

\begin{tabular}{|c|c|}
\hline & Mean \\
\hline Impersonation & .39 \\
\hline B10 - Sending unwanted content to other people's computers without their permission. & .39 \\
\hline $\begin{array}{l}\text { B11 - Editing photos or videos of others to diffuse them through social networks or YouTube to humiliate } \\
\text { them or make fun of them. }\end{array}$ & .34 \\
\hline B14 - Slandering others through the internet, telling lies about others to discredit them. & .39 \\
\hline B15 - Spreading rumours about others to harm them. & .39 \\
\hline B16 - Sharing personal information about others online without their consent. & .42 \\
\hline B17 - Lying to others in order to get their personal information and then publishing it on the internet. & .30 \\
\hline $\begin{array}{l}\text { B18 - Publicising personal information about others through e-mails or instant messaging tools without their } \\
\text { consent. }\end{array}$ & .34 \\
\hline B19 - Using personal information of others without their permission. & .37 \\
\hline B20 - Publishing personal photographs and videos of others without their permission. & .43 \\
\hline B21 - Pretending to be someone else in the online world. & .55 \\
\hline B22 - Speaking on behalf of others using their nickname without their knowledge. & .47 \\
\hline B23 - Using webcam images of others without their consent. & .30 \\
\hline Cyberstalking and harassment & .36 \\
\hline B31 - Making anonymous calls to scare or frighten others. & .47 \\
\hline B32 - Blackmailing or threatening others with calls or messages. & .38 \\
\hline $\begin{array}{l}\text { B33 - Blackmailing others to make them do things they do not want to do or to prevent them from diffusing } \\
\text { your confidential information on the internet. }\end{array}$ & .32 \\
\hline B34 - Disturbing others and forcing them to chat on instant messaging programs. & .43 \\
\hline B35 - Sending obscene e-mails. & .31 \\
\hline B36 - Sending obscene images while using a webcam. & .32 \\
\hline B37 - Sending sexual proposals to people I know/I do not know. & .38 \\
\hline B38 - Harassing others sexually by cell phone or on the Internet. & .30 \\
\hline Flaming & .50 \\
\hline B3 - Sending insulting e-mails or instant messages. & .50 \\
\hline B5 - Urging someone to vote for or sign up to a religious, political or sports group. & .37 \\
\hline B7 - Inviting others to social applications to gossip or have inappropriate chats. & .64 \\
\hline B8 - Using software with the aim to get personal information of others. & .56 \\
\hline Elimination & .51 \\
\hline B25 - Intentionally excluding someone from an online group/chat room. & .78 \\
\hline B27 - Not letting someone join a conversation. & .76 \\
\hline B28 - Acting like as if another person does not exist. & .96 \\
\hline B29 - Intentionally leaving others out of online groups. & .88 \\
\hline
\end{tabular}


mum value required for a model fit. The reliability analysis resulted in values that ranged between .823 and .956 for the internal consistency method and values that ranged between .782 and .936 for the splithalf method. The output values of both methods exceeded the minimum value of .700 , as recommended by Nunally (1978).

A review of the literature resulted in a variety of factors and items being discovered. The sub-factors and items were impersonations (13 items), cyberstalking, and harassment (nine items), flaming (four items) and elimination (four items). Studies conducted by Del Rey (2015), Shapka and Maghsoudi (2017), and Cetin et al. (2011) found that spreading rumours, humiliating others, creating fake identities, and sharing personal information of others were examples of the sub-factor impersonation. Previous studies such as those conducted by Antoniodou et al. (2016), Lam and Li (2013), and Lee et al. (2015) also confirmed that cyberstalking and harassment were related to activities such as blackmailing, threatening, sending obscene e-mails, and making anonymous calls to scare or frighten others. Meanwhile, Udris (2014) and Coelho et al. (2016) found that examples of flaming-related activities were inviting others to social applications to gossip or having inappropriate chats and insulting others. Finally, Calvete et al. (2010) and Stewart et al. (2014) discovered that elimination-related activities included acts such as intentionally excluding others from online groups or chat rooms and intentionally leaving others out of online groups. To sum up, all of the studies proved the reliability and validity of the sub-factors in being able to reliably and validly measure cyberbullying activities among Malaysian youths. It is interesting to note that the re- sults confirmed that within a Malaysian context, similar sub-factors namely impersonation, cyberstalking and harassment, flaming and elimination could also be applied to an older group of Malaysian youths (15 to 40 years old).

In this study, it was discovered that cyberbullying activities such as pretending to be others in the online world and making anonymous calls to scare or frighten others were activities which were most frequently carried out by Malaysian youths. This study has theorised that the anonymity of their virtual identities might be the main stimulator for them doing so. The findings showed that inviting others to social applications to gossip, having inappropriate chats, and acting like another person did not exist were also frequent acts carried out among Malaysian youths. The findings were not surprising as the perpetrators might be stimulated by the fact that the virtual world would offer them several advantages such as an extra degree of protection and an anonymous identity (Lee and Shin, 2017; Chapin and Coleman, 2017). Moreover, those who do not have the courage to commit traditional bullying might turn to cyberbullying (Balakrishnan, 2015; Chapin and Coleman, 2017).

\section{LIMITATION AND FUTURE STUDIES}

The present study has several limitations that should be considered before further research can be extended. First, the study focused on a youth age group between 15 and 40 years old. In the future, studies should be developed to measure cyberbullying among respondents from an older age group of 41 years and above and a younger group of 15 years and below. Second, the 
study only focused on one state in Peninsular Malaysia. In order to ensure future studies provide a better representation of the phenomenon, more states and districts should be involved; future studies should include districts from Sabah and Sarawak as well. Third, the study relied on a self-report questionnaire, which increased the possibility of reporting bias, which may have occurred in order to provide socially desirable responses.

\section{CONCLUSION}

In response to an inadequate number of studies and the lack of suitable instruments measuring cyberbullying within the Malaysian context, this study has succeeded in developing and validating an instrument measuring cyberbullying among Malaysian youths. The initial version of the instrument consisted of 41 items. Nevertheless, after the process of content and face validity, EFA and CFA, the final version of the instrument consisted of 30 items which measured cyberbullying activities among Malaysian youths. The EFA managed to produce four sub-factors of cyberbullying; namely, impersonation (13 items), cyberstalking and harassing (nine items), flaming (four items), and elimination (four items). The measurement model then excluded a total of eight items as they failed to exceed the value recommended. The resultant analysis of the measurement model confirmed that the model was fit. The reliability analyses which utilised the internal consistency and split-half method confirmed that all the subfactors exceeded the recommended value of .700 as suggested by Nunnally (1978). This study represents a significant contribution to the literature as the number of reliable and validated instrument for cyberbullying in
Malaysian perspective is still lacking. By taking consideration of factors such as impersonation, cyberstalking and harassing, flaming, and elimination would enable researchers to determine which of these factors possess the strongest influences on bystander responses.

\section{ACKNOWLEDGEMENT}

The researchers would like to thank the Ministry of Higher Education Malaysia for funding the study under its Fundamental Research Grant Scheme (05-01-161870FR).

\section{REFERENCES}

Alvarez-Garcia, D., Barreiro-Collazo, A., Nunez, J.C., \& Dobarro, A. (2016). Validity and reliability of the Cyberaggression Questionnaire for Adolescents (CYBA). The European Journal of Psychology Applied to Legal Context, 8, 69-77.

Antoniadou, N., Kokkinos, C.M., \& Markos, A. (2016). Development, construct validation and measurement invariance of the Greek cyberbullying/victimisation experiences questionnaire (CBVEQ-G). Computers in Human Behavior, 65, 380-390.

Aricak, O.T., \& Ozbay, A. (2016). Investigation of the relationship between cyberbullying, cybervictimization, alexithymia and anger expression styles among adolescents. Computers in Human Behavior, 55, 278-285.

Balakrishnan, V. (2015). Cyberbullying among young adults in Malaysia: The roles of gender, age and Internet fre- 
quency. Computers in Human Behavior, 46, 149-157.

Balakrishanan, V. (2017). Unraveling the underlying factors SCulPT-ing cyberbullying behaviours among Malaysian young adults. Computers in $\mathrm{Hu}$ man Behavior, 75, 194-205.

Bauman, S., Toomey, R.B., \& Walker, J.L., (2013). Associations among bullying, cyberbullying, and suicide in high school students. Journal of Adolescence, 36, 341-350.

Bentler, P.M., \& Bonnet, D.C. (1980). Significance tests and goodness of fit in the analysis of covariance structures. Psychological Bulletin, 88 (3), 588606.

Bentler, P.M. (1990). Comparative fit indexes in structural models. Psychological Bulletin, 107 (2), 238-46.

Calvete, E., Orue, I., Estevez, A., Villardon, L., \& Padilla, P. (2010). Cyberbullying in adolescents: Modalities and aggressors' profile. Computers in Human Behavior, 26 (5), 1128-1135.

Cetin, B., Yaman, E., \& Peker, A. (2011). Cyber victim and bullying scale: A study of validity and reliability. Computers and Education, 57, 2261-2271.

Chau, P. (1997). Re-examining a model for evaluating information center success using a Structural Equation Modelling approach. Decision Sciences, 28 (2), 309-334.

Chapin, J., \& Coleman, G. (2017). The cycle of cyberbullying: Some experience required. Retrieved from: http://ac.els-

cdn.com/S0362331917300319/1-s2.0S0362331917300319- main.pdf?_tid=1d139c06-605c-11e7-

b223-

00000aab0f02\&acdnat $=1499133620$ 6d4e79fbfd3e109627795f8f0cb69ffb

Coelho, V.A., Sousa, V., Marchante, M., Bras, P., \& Ramoa, A.M. (2016). Bullying and cyberbullying in Portugal: Validation of a questionnaire and analysis of prevalence. School Psychology International, 37, 223-239.

Del Rey, R., Casas, J.A., Ortega-Ruiz, R., Schultze-Krumbholz, A., Scheithauer, H., Smith, P., Thompson, F., Barkoukis, V., Tsorbatzoudis, H., Brighi, A., Guarini, A., Pyzalski, J., \& Plichta, P. (2015). Structural validation and cross-cultural robustness of the European Cyberbullying Intervention Project Questionnaire. Computers in Human Behavior, 50, 141147.

Digi (2015). Digi cybersafe in school. Retrieved on 11 January 2018, from http://new.digi.com.my/cs/site_templ ate/digi/images/cybersafe/dcpinfograp hic-bm.jpg

Garaigordobil, M. (2015). Psychometric Properties of the Cyberbullying Test, a Screening Instrument to Measure Cyber-victimization, Cyberaggression, and Cyberobservation. Journal of Interpersonal Violence.

Hair, J.F., Black, W.C., Babin, B.J., \& Anderson, R.E. (2010). Multivariate data analysis. Seventh Edition. PrenticeHall, Upper Saddle River, New Jersey.

Hatcher, L. (1994). A step-by-step approach to using the SAS System for factor analysis and structural equation 
modelling. Cary, NC: SAS Institute Inc.

Hinduja, S., \& Patchin, J.W. (2010). Bullying, cyberbullying, and suicide. Archives of Suicide Research, 14, 206221.

Kokkinos, C.M., Antoniadou, N., \& Markos, A. (20164). Cyber-bullying: An investigation of the psychological profile of university student participants. Journal of Applied Developmental Psychology, 35 (3), 204-214.

Lam, L.T., \& Li, Y. (2013).The validation of the E-Victimisation Scale (E-VS) and the E-Bullying Scale (E-BS) for adolescents. Computers in Human Behavior, 29, 3-7.

Landoll, R.R., La Greca, A.M., Lai, B.S., Chan, S.F., \& Herge, W.M. (2015). Cyber victimisation by peers: Prospective associations with adolescent social anxiety and depressive symptoms. Journal of Adolescence, 42, 77 86.

Lee, J., Abell, N., \& Holmes, J.L. (2015). Validation of measures of cyberbullying perpetration and victimisation in emerging adulthood. Research on Social Work Practice, 27, 456-467.

Lee, C., \& Shin, N. (2017). Prevalence of cyberbullying and predictors of cyberbullying perpetration among Korean adolescents. Computers in Human Behavior, 68, 352-358.

Mohamad Salleh, N., \& Zainal, K. (2014). Bullying among secondary school students in Malaysia: A case study. International Education Studies, 7 (13), 184-191.
Nunnally, J.C (1978). Psychometric theory. 2nd Edition. Mc-Graw Hill, New York.

Schenk, A.M., Fremouw, W.J., \& Keelan, C.M. (2013). Characteristics of college cyberbullies. Computers in $\mathrm{Hu}$ man Behavior, 29, 2320-2327.

Segars, A.H., \& Grover, V. (1993). Reexamining perceived ease of use and usefulness: a confirmatory factor analysis. MIS Quarterly, 17 (4), $517-$ 525.

Smith, P.K., Mahdavi, J., Carvalho, M., Fisher, S., Russell, S., \& Tippett, N. (2008). Cyberbullying: Its nature and impact in secondary school pupils. The Journal of Child Psychology and Psychiatry, 49 (4), 376-385.

Shapka, J.D., \& Maghsoudi, R. (2017). Examining the validity and reliability of the cyber-aggression and cybervictimisation scale. Computers in Human Behavior, 69, 10-17.

Stewart, R.W., Drescher, C.F., Maack, D.J., Ebesutani, C., \& Young, J. (2014). The development and psychometric investigation of the cyberbullying scale. Journal of Interpersonal Violence, 29, 2218-2238.

Topcu, C., \& Erdur-Baker, O. (2010). The Revised Cyber Bullying Inventory (RCBI): validity and reliability studies. Procedia - Social and Behavioral Sciences, 5, 660-664.

Udris, R. (2014). Cyberbullying among high school students in Japan: Development and validation of the Online Disinhibition Scale. Computers in Human Behavior, 41, 253-261. 
Akmar Hayati Ahmad Ghazali et al

Vranjes, I., Baillien, E., Vandebosch, H., Yubero, S., Navarro, R., Elche, M., LarErreygers, S., \& De Witte, H. (2017). ranaga, E., \& Ovejero, A. (2017). The dark side of working online: ToCyberbullying victimisation in higher wards a definition and an Emotion education: An exploratory analysis of Reaction model of workplace cyberits association with social and emobullying. Computers in Human Behavior, 69, 324-334. tional factors among Spanish students. Computers in Human Behavior, 75, 439-449. 